This version of the referenced work is the post-print version of the article-it is NOT the final published version nor the corrected proofs. If you would like to receive the final published version, please send a request to any of the authors and we will be happy to send you the latest version. Moreover, you can contact the publisher's website and order the final version there, as well.

The current reference for this work is as follows:

Silic, M., Back, A., \& Sammer, T. (2017). Employee acceptance and use of unified communications and collaboration in a cross-cultural environment. In Remote Work and Collaboration: Breakthroughs in Research and Practice(pp. 1-22). IGI Global.

$*=$ corresponding author

If you have any questions, would like a copy of the final version of the article, or would like copies of other articles we've published, please contact any of us directly, as follows:

- Mario Silic (mario.silic@unisg.ch) 


\title{
Employee Acceptance and Use of Unified Communications \& Collaboration in a Cross- Cultural Environment
}

\author{
Mario Silic \\ Institute of Information Management \\ University of St.Gallen \\ Müller-Friedberg-Str. 8 \\ 9000 St.Gallen \\ Switzerland \\ Tel: +385-91-460-3892 \\ Fax: +41-71-224-2716 \\ Email: mario.silic@student.unisg.ch \\ Web page: http://www.iwi.unisg.ch \\ Andrea Back \\ Institute of Information Management \\ University of St.Gallen \\ Müller-Friedberg-Str. 8 \\ 9000 St.Gallen \\ Switzerland \\ Tel: +41-71-224-2545 \\ Fax: +41-71-224-2716 \\ Email: andrea.back@unisg.ch \\ Web page: https://www.alexandria.unisg.ch/Personen/Andrea_Back \\ Thomas Sammer \\ Institute of Information Management \\ University of St.Gallen \\ Mueller-Friedberg-Str. 8 \\ 9000 St.Gallen \\ Switzerland \\ Tel: +41-71-224-3870 \\ Fax: +41-71-224-2716 \\ Email: thomas.sammer@unisg.ch \\ Web page: http://www.iwi.unisg.ch
}




\section{Abstract}

At the tip of the iceberg of the global financial crisis organizations are looking for economies of scale to survive in these challenging times. The Unified Communications and Collaboration $(U C \& C)$ platform is the perfect answer to support an organization's new strategies, aiming to increase employee productivity while decreasing costs. Our study combines recent collaboration research theories with the Unified Theory of Acceptance and Ase of Technology (UTAUT). We aim to close the existing research gap by extending previous research with a cross-cultural dimension. We conducted an international field study in 34 countries involving 120 employees who were users of UC\&C technology. We found that the UTAUT constructs are mainly validated in areas in which results suggest that performance expectancy and social influence are the most influential drivers in employee acceptance and use of $U C \& C$ in organizations.

Keywords: UTAUT; collaboration theory; cross-culture; UC\&C technology; Microsoft Lync

\section{INTRODUCTION}

The use of Unified Communications and Collaboration (UC\&C) has become an integral part of one's professional life. According to the 2012 survey that was conducted by IDG Enterprise, the increase in the adoption of, and investment in, UC\&C technology is becoming more observed; specifically in enterprise organizations, in which the biggest trigger is the explosion of consumer devices. The ability to communicate and collaborate faster, and from virtually any point, brings an unprecedented value to the corporation's goals: flexibility, interoperability, efficiency and productivity. The UC\&C can be defined as a joint venture between the communication process with collaboration tools that utilize real-time information access: instant messaging (IM), presence information (user online status), video and audio conferencing, telephony, data sharing, call control and speech recognition; and non-real time information sources such as: email, fax, SMS, etc.

Different components of UC\&C, such as instant messaging (IM), have already been studied from an individual perspective (Baškarada \& Koronios, 2012; Zhang, Köbler, Tremaine, and Milewski, 2010; Lou, Chau \& Li, 2005; Anderson, Schwager \& Kerns, 2006). The adoption and utilization of collaboration technologies in large organizations that support task-oriented collaboration has been widely explored by Pervan, Bajwa and Lewis (2005). Other research has also pointed to the influence of organizational factors on the technology adoption of UC\&C. (McAvoy \& Butler, 2006; Bajwa, Lewis, Pervan \& Lai, 2005; Bajwa et al., 2008; Straub, Loch, Evaristo, Karahanna \& Srite, 2002).

However, current studies of UC\&C adoption in enterprise in cross-cultural environments are still rare. On one hand, the focus has mainly been on the organizational factors, which correlate to the culture. Several studies analyzed factors either from an individual or national perspective, without putting the spotlight on other aspects, such as culture. On the other hand, a current research gap exists in the understanding of drivers that lead to employees' acceptance of UC\&C technology.

This research aims to fill the current knowledge gap by answering three important questions regarding employee acceptance and use of UC\&C in enterprise in cross-cultural environments:

RQ1: What are the drivers of employee acceptance of UC\&C in enterprise? 
RQ2: What other factors influence employee acceptance of UC\&C in enterprise?

RQ3: Will the adoption of the UC\&C technology drive employee productivity?

This research aims to analyze employees' acceptance and use of UC\&C in their professional environment by taking into account their cultural background. This study builds on the model proposed by Brown, Dennis, and Venkatesh (2010). This model has been used by Brown et al. (2010) and it presents integrated theories from the collaboration research with the Unified Theory of Acceptance and Use of Technology (UTAUT) model that was developed by Venkatesh, Morris, Davis and Davis (2003). To the best of our knowledge, this is the first empirical study that has extended the previous work done by Brown et al. (2010). We have added cross-cultural constructs into the context of an organization. After synthesizing with the previous research and theory, we propose a research model that will help us explain the adoption of technology by employees; we will also discuss the use and analysis of the cross-cultural construct that investigates relationships across different countries.

Firstly, we will analyze the existing research theory on collaboration and the UTAUT model and précis the research model with the hypotheses. Secondly, we will focus on the research methodology, followed by the data analysis and its results. Finally, we will discuss the findings and make conclusions.

\section{RELATED THEORY}

We will analyze relevant prior research that will be used to build the theoretical foundations for this research. Our focus will be on technological innovation and collaboration technology. There is a very strong relationship between the two areas. Kraut posits that both utility and certain normative factors influence both the success and failure of new organizational communication systems - these normative factors relate to the social influence phenomenon where users tend to use a certain system more when more people within the same work group are using them (Kraut, Rice, Cool \& Fish, 1998).

\section{Technology adoption}

Technology acceptance is one of the most well-researched areas in the IS field. Several technology acceptance models have been developed in the last decade which have been used to explain the theoretical background of user acceptance and use. In Table 1 we summarize different models that have been developed.

For the purpose of this research we are using the UTAUT model extended by the collaboration constructs as proposed by Brown et al. (2010). Brown argues that effectiveness and efficiency motives correspond directly to the core underpinnings of performance expectancy and effort expectancy respectively. This makes UTAUT particularly suitable as the basis for the model development. Furthermore, Venkatesh et al. (2000) found that the UTAUT model explains seventy percent of the variance in user intentions to use information technology, thereby proving its robustness. The UTAUT model suggests four constructs that play a key role in understanding a user's acceptance and use: performance expectancy (PE), effort expectancy (EE), social influence (SI) and facilitating conditions (FC). 
Table 1 Technology Acceptance models

\begin{tabular}{ll}
\hline Model & Author \\
\hline Theory of Reasoned Action & Fishbein \& Ajzen (1975) \\
TAM & $\begin{array}{l}\text { Davis et al. 1989, Venkatesh \& Davis } \\
(2000)\end{array}$ \\
Motivational Model & Vallerand (1997), Davis et al. (1992) \\
TPB & Ajzen (1991) \\
Combined TAM-TPB & Taylor \& Todd (1995) \\
Model of PC Utilization & Thompson et al. (1991) \\
Innovation Diffusion Theory & Rogers 1995, Moore \& Benbasat (1996) \\
Social Cognitive Theory & Bandura (1986) \\
Unified Theory of Acceptance and & Venkatesh et al.(2003) \\
Use of Technology (UTAUT). &
\end{tabular}

\section{Collaboration technology and culture}

According to Brown et al. (2010) a variety of terms have been used to refer to collaboration technology over the years-such as group decision support systems, group support systems, electronic meeting systems, groupware, computer-supported cooperative work and negotiation support systems - but these, as well as specific systems, such as e-mail, voice mail, and videoconferencing, are generally encompassed under the larger umbrella term of collaboration technology. Collaboration technology can be simply defined as hardware, software and applications that have enabled the work of collaboration technology (Camarinha-Matos et al., 2009).While collaboration technology research has been fairly well-represented in the existing literature (Fink, 2007; Pallot, Martínez-Carreras \& Prinz, 2010; Fjermestad \& Hiltz, 1998; Fjermestad \& Hiltz, 2000), its main focus, until recently, was on decision systems. With the growing needs of organizations to decrease their costs and increase their employees' performance, productivity, flexibility and efficiency, collaboration technology and collaboration as a unique process saw tremendous development. In their study in 2007, Frost and Sullivan (2007) found that collaboration is a key driver of business performance in many organizations around the world. Moreover, virtual interaction is becoming increasingly commonplace and the percentage of time employees work virtually and the need for collaboration technology use are both increasing (Konradt \& Hoch, 2007; Drakos, 2009; Romano, Pick \& Roxtocki, 2007). The range and scope of collaboration has been clearly defined (Smith, Heather, McKeen \& James, 2011) with explanations as to who is collaborating, what they are collaborating on, where they are collaborating and what the collaboration process looks like. For the collaboration technology to succeed, MacCormack and Forbath (2008) defined four components of the collaboration which must fit and work mutually: people, program, processes and platforms. Among these four pillars, people represent the most important one, where communication skills, especially in virtual environments and across different cultures, are of high importance (Romano et al., 2007). In multi-cultural environments, the implementation of technology has never been of higher importance as organizations are looking for cost-efficiency and cost-reduction in order to achieve economies of scale. In that context, the enablement of collaboration technology has been 
propelled to a new level but it has also brought a new challenge to deal with: how to effectively cope with different physical locations and cultures across the organization? The cultural implications of the user acceptance of technology have been widely researched at different levels: national, organizational and subunit. Al-Gahtani (2007) researched the similarities and differences between the North American and Saudi Arabian validations of UTAUT in terms of cultural factors that affected the organizational acceptance of technology. Chow, Deng and Ho (2000) found that Chinese employees are much less willing to share knowledge with people who do not belong to their social group.

It is always very challenging to define what culture is and how to measure it (Dent \& Green, 1985; Pettigrew, 1990; Smircich, 1983). The role and impact of organizational culture has been studied in the context of information technology adaptation (Gefen, Geri \& Paravastu, 2007; Duranti \& Carvalho de Almeida, 2012; Harper \& Utley, 2001; Fedrick, 2001), information technology adoption and diffusion (Dasgupta, Agarwal, Ioannidis \& Gopalakrishnan, 1999) and the flexibility of the information technology infrastructure (Syler, 2003). Cabrera et al. (2001) argue that successful technology assimilation requires either the technology to fit the organizational culture or the culture to be shaped to fit the behavioral requirements of the technology. Organizations in which the culture can be seen as open and flexible and those which have a long-term orientation have been observed as facilitating an easier adoption of the new technology system (Kitchell, 1995).

\section{RESEARCH METHODOLOGY}

This research focuses on employee acceptance and use of UC\&C in the professional environment. The UTAUT model, extended by collaboration technology constructs proposed by Brown et al. (2010), is used as the basis for our research model. According to Brown, there is nothing in UTAUT itself that directly helps us in understanding what leads to the adoption of collaboration technology; she argues that UTAUT mediates the relationship between the characteristics of a use situation and the ultimate adoption and use of the technology (Brown et al., 2010).

\section{Research Hypotheses}

Performance expectancy is related to the job performance and defines the degree to which an individual believes that using the system will impact on his/her increased job performance. Venkatesh et al. (2003) suggest that gender and age moderate the effect of performance expectancy, where it seems that there is a greater focus on tasks performed by younger workers, especially men. This same pattern can be expected in the effect of performance expectancy on the intention to use a collaboration technology, as such technologies have the potential to be minimally disruptive to one's work in terms of time relative to alternatives, such as a face-to-face meeting, and can potentially help to increase productivity (Brown, Dennis \& Venkatesh, 2010). Therefore, we hypothesize: 
Hypothesis 1a: The effect of performance expectancy on the intention to use UC\&C technology will be moderated by gender and age, such that it is strongest for younger men.

Facilitating conditions are the extent to which an individual believes that an organizational and technical infrastructure exists to support the use of the system. If organizational support for collaborating via technology is lacking, individuals will more likely turn to the collaboration modes that are supported within the organization (Brown et al., 2010). Therefore, we hypothesize:

Hypothesis 1b: The effect of facilitating conditions on UC\&C technology use will be moderated by age and experience, such that the effect is stronger for older users, particularly those with little experience.

Collaboration technologies with high social presence convey a social and personal environment for communication (Brown et al., 2010). Social presence is influenced by a technology's capacity to transmit no word cues (e.g. voice inflection) and nonverbal cues (e.g. gestures, facial expressions) (Brown et al., 2010). Karahanna and Straub (1999) suggest that there is a positive relationship between social presence and usefulness (performance expectancy). Therefore, we hypothesize:

Hypothesis 2a: Social presence will positively influence performance expectancy. Hypothesis 2b: Social presence will positively influence effort expectancy.

Immediacy of communication is the degree to which a collaboration technology enables the user to quickly communicate with others. Immediacy of communication is an important factor in the choice to use a collaboration technology (Karahanna \& Straub, 1999, Straub \& Karahanna, 1998). Technologies with higher immediacy capability will be perceived to be more effective and efficient and, thus, will be perceived to have greater performance and effort expectancies (Brown et al., 2010). Therefore, we hypothesize:

Hypothesis 2c: Immediacy of communication will positively influence performance expectancy. Hypothesis $2 d$ : Immediacy of communication will positively influence effort expectancy.

Concurrency refers to the ability of an individual to perform other tasks in parallel while using collaboration technology. The ability to work concurrently should be reflected in favorable assessments of performance and effort expectancies given that enabling concurrency, when needed, should lead to greater effectiveness, efficiency and satisfaction, which should contribute to better performance and effort expectancy cognitions (Brown et al., 2010).

Hypothesis 2e: Concurrency will positively influence performance expectancy. Hypothesis 2f: Concurrency will positively influence effort expectancy.

Experience that is related to the degree to which the worker has already acquired certain experience with technology adoption as well as the use from other systems is crucial. Dennis and Garfield (2003) argue that performance will be improved as the individual's experiences with technology are increasingly becoming easier. In the same way, the computer self-efficacy 
construct can be seen as a factor influencing the users' perception of performance and effort expectancies (Venkatesh, 2000; Venkatesh \& Davis, 1996). Therefore, we hypothesize:

Hypothesis 3a: UC\&C technology experience will positively influence performance expectancy. Hypothesis 3b: UC\&C technology experience will positively influence effort expectancy. Hypothesis 3c: Computer self-efficacy will positively influence performance expectancy. Hypothesis 3d: Computer self-efficacy will positively influence effort expectancy.

Familiarity with communication partners refers to knowledge of one's co-workers where the same group of people will be using the collaboration technology in order to communicate faster and focus more quickly on the task (DeSanctis \& Poole, 1994). Therefore, we hypothesize:

Hypothesis 3e: Familiarity with communication partners will positively influence performance expectancy.

Hypothesis 3f: Familiarity with communication partners will positively influence effort expectancy.

Dennis \& Gallupe (1993) posit that situational characteristics are about the context in which the collaboration technology is implemented. In this paper, the focus is on the influence of peers and superiors. Two other components are: resource-facilitating and technology-facilitating conditions which are expected to positively influence the perception of facilitating conditions; as the resources and technology that are available to support system use increase, so will the perception of facilitating conditions (Taylor \& Todd, 1995).

Therefore, we hypothesize:

Hypothesis 4a: The influence of peers will positively influence the perception of social influence. Hypothesis 4b: The influence of superiors will positively influence the perception of social influence.

Hypothesis 4c: Resource-facilitating conditions will positively influence the perception of facilitating conditions.

Hypothesis 4d: Technology-facilitating conditions will positively influence the perception of facilitating conditions.

Venkatesh (2000) posits that there is a positive direct effect of behavioral intention on use. Therefore, we hypothesize:

Hypothesis 5: Behavioral intention will positively influence use.

Our research model is presented in Figure 1. 


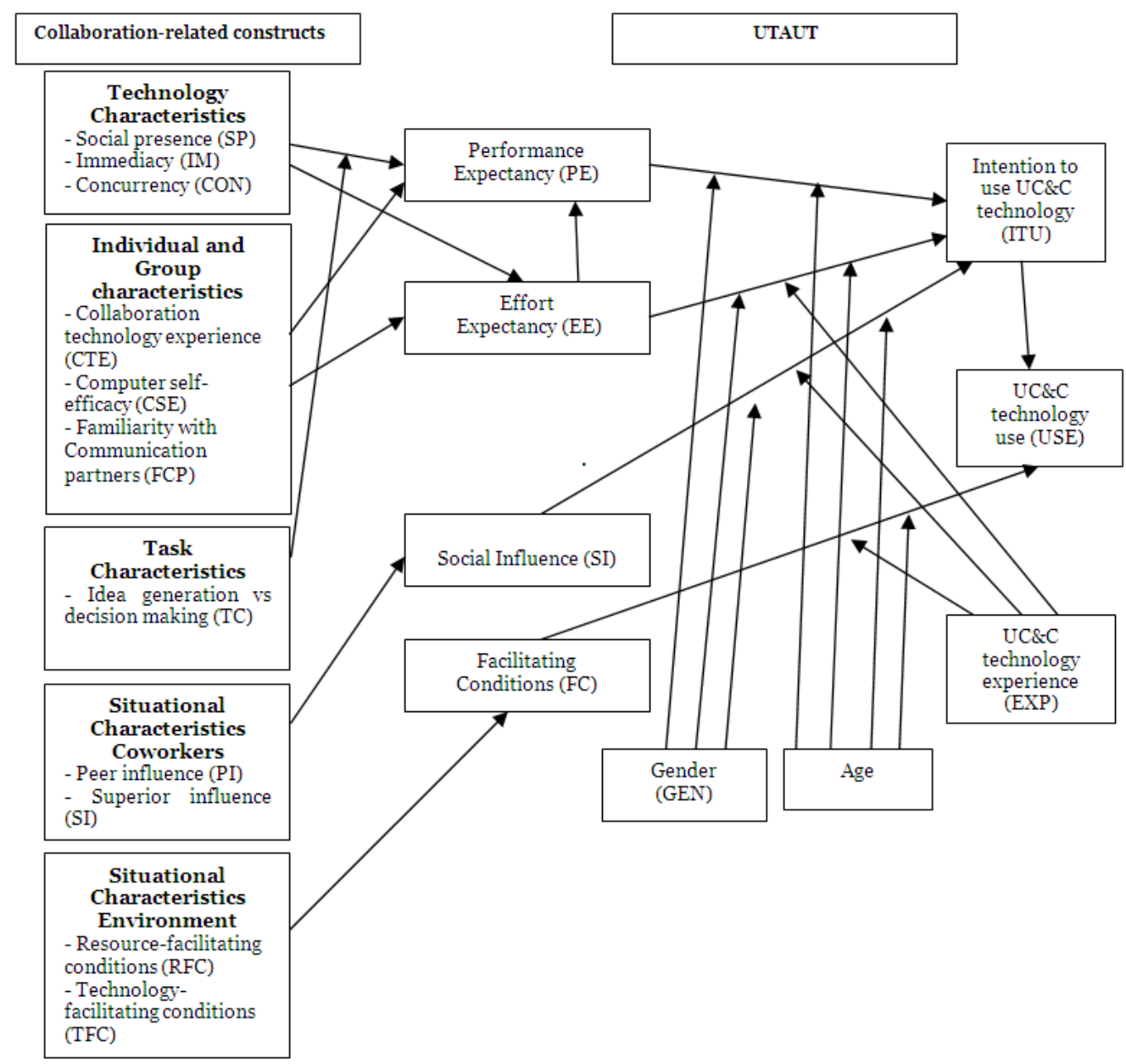

Figure 1: Research model

\section{RESEARCH METHOD}

\section{Data Collection}

For the purpose of this research paper the survey method was used to collect data. The survey was held in a Fortune 500 financial company which has offices in 42 different countries. The respondents were company employees who came from different functional departments: Accounting, Marketing, Operations, Management, Call Centers, Compliance, Legal, IT and Finance. The target system was the Microsoft Lync software. All employees have access to full Lync features including chat, video conference and audio conference.

\section{Participants}

An online questionnaire invitation was sent to 250 employees in 39 different countries; all contacted employees were users of UC\&C technology. 


\begin{tabular}{|c|c|c|c|c|c|}
\hline Country & $\begin{array}{l}\text { Responde } \\
\text { nts }\end{array}$ & Country & $\begin{array}{l}\text { Respondent } \\
\mathrm{S}\end{array}$ & Country & Respondents \\
\hline Mexico & 12 & Morocco & 4 & Pakistan & 2 \\
\hline Austria & 10 & Sweden & 4 & Philippines & 2 \\
\hline Costa Rica & 9 & Canada & 3 & Spain & 2 \\
\hline United & 7 & Ireland & 3 & Australia & 1 \\
\hline States & 6 & Romania & 3 & China & 1 \\
\hline India & 5 & South & 3 & Greece & 1 \\
\hline Argentina & 5 & Africa & 3 & Hong Kong & 1 \\
\hline Brazil & 5 & Turkey & 3 & Italy & 1 \\
\hline Croatia & 5 & UAE & 2 & Netherlands & 1 \\
\hline Peru & 5 & Banglades & 2 & Poland & 1 \\
\hline Russia & 4 & h & 2 & Taiwan & 1 \\
\hline Lithuania & & $\begin{array}{l}\text { Cnile } \\
\text { Germany }\end{array}$ & & Thailand & 1 \\
\hline
\end{tabular}

\section{Table 2 Summary of Country respondents}

Of 250 contacted employees, we received 135 responses from people in 32 different countries. Of the 135 responses, 5 were not valid; thus, they were removed. We also excluded 10 respondents whose responses indicated that their usage of UC\&C was nonexistent. We retained a total of 120 responses as the final sample, which was further analyzed. Table 2 shows the country distribution among participants. The disparity in the number of respondents between different countries is due to the fact that the company has a number of small offices (2-5 people). Of the 120 participants, 52 were women (43.4 percent) and 68 men $(56.6 \%)$; the average age of the participants was $35.23(\mathrm{SD}=8.87)$ and $33.16(\mathrm{SD}=7.33)$ in the initial and follow-up surveys, respectively. Table 3 illustrates the distribution.

\begin{tabular}{|c|c|c|c|c|c|c|c|c|}
\hline $\begin{array}{l}\text { Characteri } \\
\text { stics }\end{array}$ & $\begin{array}{l}\mathrm{Ag} \\
\mathrm{e}\end{array}$ & $(\%)$ & Gender & $\begin{array}{l}\text { Number } \\
(\mathrm{N}=120)\end{array}$ & $(\%)$ & $\begin{array}{l}\text { Experience with } \\
\text { Computers }\end{array}$ & $\begin{array}{l}\text { Number } \\
(\mathrm{N}=120)\end{array}$ & $(\%)$ \\
\hline$<20$ & 1 & $0.8 \%$ & Male & 68 & $\begin{array}{c}56.6 \\
\%\end{array}$ & $<3$ years & 3 & $\begin{array}{l}2.5 \\
\%\end{array}$ \\
\hline $20-30$ & 31 & $25.8 \%$ & Female & 52 & $\begin{array}{l}43.4 \\
\% 4\end{array}$ & $3-5 y$ & 18 & 15 \\
\hline $31-40$ & 66 & $55 \%$ & & & & $6-9 y$ & 45 & $\begin{array}{l}37 . \\
5 \%\end{array}$ \\
\hline \multirow[t]{2}{*}{$>40$} & 22 & $18.4 \%$ & & & & $10-19 y$ & 42 & $\begin{array}{l}35 \\
\%\end{array}$ \\
\hline & & & & & & $>19 y$ & 12 & $\begin{array}{l}10 \\
\%\end{array}$ \\
\hline
\end{tabular}

Table 3 Sample Characteristics

\section{Pre-tests}

We conducted pre-tests to the survey so we could understand its validity. Seven personal interviews were conducted and were combined with ten online surveys to check the validity of the proposed measures and constructs. Respondents were chosen from different countries and 
cultures to ensure a good representative sample. It was highlighted by thirty per cent of the online responders that the survey was too long. Finally, based on the returned responses, instrument reliability and validity were checked, with the conclusion that the instrument possessed good reliability and validity.

\section{RESULTS}

Our research model was analyzed using WarpPLS 3.0, a powerful PLS-based structural equation modeling (SEM) software. The partial least squares (PLS) method was used for the latent variable path (LVP) analysis.

\section{The Measurement Model}

Reliability results are presented in Table 4. The composite reliabilities of the different measures range from 0.84 to 0.97 , which exceeds the recommended threshold value of 0.70 . Also, following the recommendation of Fornell and Larcker (1981), the average variance extracted (AVE) for each variable construct exceeds 0.50 .

\begin{tabular}{lll}
\hline Variable constructs & AVE & Composite Reliability \\
\hline Computer Self-efficacy (CSE) & 0.707 & 0.879 \\
Concurrency (CON) & 0.899 & 0.964 \\
Effort Expectancy (EE) & 0.67 & 0.853 \\
Facilitating Conditions (FC) & 0.72 & 0.837 \\
Familiarity with Communication Partners (FCP) & 0.74 & 0.895 \\
Immediacy (IM) & 0.692 & 0.871 \\
Intention to Use (ITU) & 0.949 & 0.982 \\
Peer Influence (PI) & 0.874 & 0.933 \\
Performance Expectancy (PE) & 0.782 & 0.915 \\
Resource-Facilitating Conditions (RFC) & 0.711 & 0.88 \\
Social Influence (SI) & 0.872 & 0.953 \\
Social Presence (SP) & 0.915 & 0.97 \\
Superior Influence (SUP) & 0.828 & 0.906 \\
Technology Experience (TE) & 0.665 & 0.854 \\
Technology-Facilitating Conditions (TFC) & 0.777 & 0.913 \\
Use behaviour (USE) & 0.751 & 0.9
\end{tabular}

Table 4 Assessment of the measurement model

According to the Fornell-Larcker criterion (Fornell \& Larcker, 1981), the AVE of each latent construct should be higher than the construct's highest squared correlation with any other latent construct. The discriminant validity test is shown on Table 5 where the square root of the reflective constructs' AVE is on the diagonal and the correlations between the constructs are in the lower left triangle. We observe that the discriminant validity test has been established. 


\begin{tabular}{|l|l|l|l|l|l|l|l|l|l|l|l|l|l|l|l|l|}
\hline & 1 & 2 & 3 & 4 & 5 & 6 & 7 & 8 & 9 & 10 & 11 & 12 & 13 & 14 & 15 & 16 \\
\hline SP & $\mathbf{0 . 9 6}$ & & & & & & & & & & & & & & \\
\hline IM & 0.36 & $\mathbf{0 . 8 3}$ & & & & & & & & & & & & & \\
\hline CON & 0.22 & 0.38 & $\mathbf{0 . 9 5}$ & & & & & & & & & & & & \\
\hline CSE & 0.21 & 0.14 & 0.22 & $\mathbf{0 . 8 4}$ & & & & & & & & & & & \\
\hline TE & 0.11 & 0.03 & 0.19 & 0.3 & $\mathbf{0 . 7 5}$ & & & & & & & & & & \\
\hline TFC & -0.07 & -0.18 & -0.06 & -0.12 & -0.03 & $\mathbf{0 . 8 8}$ & & & & & & & & & & \\
\hline RFC & -0.23 & -0.35 & -0.17 & -0.23 & 0.13 & 0.36 & $\mathbf{0 . 8 4}$ & & & & & & & & & \\
\hline PE & 0.49 & 0.44 & 0.34 & 0.31 & 0.18 & -0.09 & -0.3 & $\mathbf{0 . 8 8}$ & & & & & & & & \\
\hline FCP & 0.02 & 0.09 & 0.15 & 0.19 & 0.02 & 0.07 & -0.04 & 0.15 & $\mathbf{0 . 8 6}$ & & & & & & & \\
\hline ITU & 0.31 & 0.41 & 0.4 & 0.19 & 0.18 & 0.03 & -0.18 & 0.7 & 0.2 & $\mathbf{0 . 9 7}$ & & & & & & \\
\hline USE & 0.34 & 0.38 & 0.55 & 0.29 & 0.39 & -0.16 & -0.16 & 0.46 & 0.12 & 0.51 & $\mathbf{0 . 8}$ & & & & & \\
\hline SI & 0.27 & 0.24 & 0.29 & 0.16 & 0.13 & -0.12 & -0.02 & 0.42 & 0.17 & 0.32 & 0.37 & $\mathbf{0 . 9 3}$ & & & & \\
\hline PI & 0.13 & 0.03 & 0.03 & 0.09 & 0.1 & -0.2 & -0.12 & 0.17 & 0.22 & -0.04 & 0.11 & 0.53 & $\mathbf{0 . 7 9}$ & & & \\
\hline SUP & 0.18 & 0.08 & 0.26 & 0.17 & 0.15 & 0.08 & 0.07 & 0.23 & 0.31 & 0.16 & 0.4 & 0.6 & 0.44 & $\mathbf{0 . 8}$ & & \\
\hline FC & 0.05 & 0.23 & 0.22 & 0.22 & 0.36 & -0.21 & -0.18 & 0.26 & 0.25 & 0.21 & 0.29 & 0.36 & 0.38 & 0.34 & $\mathbf{0 . 7 1}$ & \\
\hline EE & 0.41 & 0.34 & 0.31 & 0.23 & 0.21 & 0.01 & -0.17 & 0.62 & 0.08 & 0.42 & 0.3 & 0.36 & 0.12 & 0.24 & 0.27 & $\mathbf{0 . 8 2}$ \\
\hline
\end{tabular}

Table 5 Discriminant validity (intercorrelations) of variable constructs

Also, Stone-Geisser Q-squared coefficients were calculated for each of the endogenous variables in the study's path model (Geisser, 1974; Stone, 1974). Endogenous variables with acceptable predictive validity have Q-squared coefficients of greater than zero (Kock, 2012). Each of the endogenous variables in the study's model exhibited Q-squared coefficients greater than zero (PE 0.49, ITU 0.57, USE 0.317, SI 0.494, FC 0.161, EE 0.311), thereby presenting acceptable predictive validity.

Furthermore, we performed a full collinearity check that was based on the variance inflation factors (VIFs) for each of the latent variables. VIFs represent the degree of multicollinearity among variables, including both indicators and latent variables (Kock, 2012). Collinearity can be vertical or lateral. Vertical collinearity is predictor-predictor latent variable collinearity in individual blocks, while lateral collinearity refers to predictor-criterion latent variable collinearity (Kock, 2012). It is recommended that VIFs be lower than 5 (Hair et al., 2010; Kline, 2010; Kock, 2012). Considering that the highest VIF score is 3.375 (Table 6), we conclude that the existence of no multicollinearity can be stated.

\begin{tabular}{|c|c|c|c|c|c|c|c|}
\hline$S P$ & $I M$ & $C O N$ & $C S E$ & $T E$ & $T F C$ & $R F C$ & $P E$ \\
\hline 1.517 & 1.593 & 1.577 & 1.314 & 1.628 & 1.386 & 1.549 & 3.375 \\
\hline FCP & ITU & USE & SI & $\mathrm{PI}$ & SUP & FC & $\mathrm{EE}$ \\
\hline 1.27 & 2.603 & 2.238 & 2.548 & 1.98 & 2.257 & 1.589 & 1.858 \\
\hline
\end{tabular}

Table 6 Full collinearity VIFs

Simpson's paradox is characterized by the fact that the correlation and path coefficient of a predictor latent variable with respect to a criterion latent variable have opposite signs (Kock, 2012; Wagner, 1982). According to Kock (2012), it means that paths having these opposite signs 
might be improbable or the direction of the relationship is reversed. In order to address Simpson's paradox in the current model, we examined all links between predictor and criterion variables. As we did not identify any paths with positive (negative) correlations or negative (positive) path coefficients, we concluded that our model does not contain any instances of Simpson's paradox.

Using WarpPLS, we checked the cross loadings where discriminant validity is established when an indicator's loading on a construct is higher than all of its cross loadings with other constructs. The results are presented in Table 6, which indicates that all items are more highly loaded on their respective construct than on any other. As shown in Table 7, all but two of the items' loadings were greater than 0.70 (all significant, $\mathrm{p}<0.001$ ). However, these items were retained because firstly, according to Chin, Marcolin and Newsted (2003), a loading would be considered acceptable if the loadings of other items for the same construct were high, and secondly, the loading was still higher than the cutoff point of 0.4 that is recommended by some scholars (i.e. Hulland, 1999; Straub, Boudreau \& Gefen, 2004).

\begin{tabular}{|c|c|c|c|c|c|c|c|c|c|c|c|c|c|c|c|c|}
\hline SP & IM & $\mathrm{CON}$ & CSE & TE & TFC & RFC & $\mathrm{PE}$ & FCP & ITU & USE & SI & PI & SUP & FC & EE & SE \\
\hline SP1 & 0.954 & -0.02 & 0.005 & 0.021 & -0.03 & 0.005 & -0.01 & -0.05 & -0 & 0.085 & 0.035 & 0.061 & 0.003 & -0.13 & 0.031 & 0.001 \\
\hline SP2 & 966 & -0.02 & -0.04 & 0.027 & -0.02 & -0.01 & -0.01 & -0.07 & -0 & 0.068 & -0.02 & -0.01 & 0.006 & 0.105 & -0.01 & 0.012 \\
\hline SP3 & 0.951 & 0.038 & 0.04 & -0.05 & 0.048 & 0.008 & 0.013 & 0.125 & 0.006 & -0.16 & -0.01 & -0.05 & -0.01 & 0.024 & -0.03 & -0.01 \\
\hline IM1 & 0.164 & 0.869 & -0.12 & -0.01 & -0.06 & -0.13 & 0.102 & 0.054 & -0.02 & 0.214 & -0.08 & -0.29 & 0.096 & 0.215 & 0.075 & -0.08 \\
\hline IM2 & -0.03 & 0.813 & 0.159 & -0.04 & -0.05 & 0.088 & 0.015 & 0.122 & -0.05 & -0.11 & -0.07 & 0.192 & -0.05 & -0.33 & 0.086 & -0.17 \\
\hline IM3 & -0.15 & 0.812 & -0.03 & 0.045 & 0.106 & 0.047 & -0.13 & -0.18 & 0.063 & -0.12 & 0.155 & 0.116 & -0.06 & 0.103 & -0.17 & 0.253 \\
\hline CON1 & 0.057 & -0.02 & 0.953 & 0.062 & -0.01 & -0.04 & -0.01 & -0.06 & -0.01 & 0.146 & -0.06 & -0.05 & 0.029 & -0.06 & 0.064 & -0.04 \\
\hline CON2 & -0.02 & -0.03 & 0.969 & -0 & 0.048 & -0.03 & -0.03 & -0.11 & -0.01 & 0.075 & -0.06 & 0.075 & 0.018 & 0.009 & -0.05 & 0.001 \\
\hline CON3 & -0.03 & 0.048 & 0.922 & -0.06 & -0.04 & 0.075 & 0.035 & 0.175 & 0.029 & -0.23 & 0.119 & -0.02 & -0.05 & 0.055 & -0.01 & 0.041 \\
\hline CSE1 & 0.059 & -0.06 & -0.07 & 0.865 & -0.15 & 0.007 & 0.092 & 0.23 & 0.007 & -0.02 & -0.02 & -0.03 & -0.02 & -0 & -0.06 & -0.04 \\
\hline CSE2 & 0.019 & 0.18 & 0.039 & 0.845 & -0.04 & 0.051 & -0.04 & -0.23 & -0.11 & 0.186 & -0.04 & -0.07 & -0.04 & 0.178 & -0.03 & -0.03 \\
\hline CSE3 & -0.08 & -0.12 & 0.029 & 0.812 & 0.202 & -0.06 & -0.06 & -0.01 & 0.107 & -0.17 & 0.062 & 0.114 & 0.062 & -0.18 & 0.092 & 0.074 \\
\hline TE2 & 0.115 & 0.046 & -0.17 & 0.055 & 0.677 & -0.27 & 0.334 & 0.16 & 0.018 & -0.15 & -0.07 & -0.02 & -0.18 & 0.061 & 0.215 & -0.01 \\
\hline TE3 & -0.06 & 0.001 & 0.096 & -0.05 & 0.87 & 0.135 & -0.16 & -0.19 & 0.1 & 0.078 & 0.006 & 0.037 & 0.073 & -0.06 & -0.16 & 0.089 \\
\hline TE4 & -0.03 & -0.04 & 0.037 & 0.01 & 0.882 & 0.077 & -0.1 & 0.065 & -0.11 & 0.034 & 0.046 & -0.02 & 0.066 & 0.008 & -0 & -0.08 \\
\hline TFC1 & 0.058 & 0.07 & 0.007 & 0.117 & 0.022 & 0.902 & 0.024 & -0 & -0.06 & -0.02 & -0.18 & -0.04 & -0.07 & 0.161 & -0.04 & -0.04 \\
\hline TFC2 & -0.07 & 0.041 & -0.03 & -0.08 & 0.143 & 0.898 & -0.17 & 0.047 & 0.111 & -0.06 & 0.016 & 0.13 & -0.06 & -0.13 & -0.09 & 0.016 \\
\hline TFC3 & 0.008 & -0.12 & 0.023 & -0.04 & -0.18 & 0.844 & 0.153 & -0.05 & -0.06 & 0.076 & 0.174 & -0.1 & 0.137 & -0.03 & 0.14 & 0.021 \\
\hline RFC1 & 0.088 & -0.02 & -0.02 & 0.061 & -0.02 & 0.013 & 0.863 & -0.13 & -0.07 & 0.064 & 0.026 & 0.039 & -0.14 & -0.08 & 0.026 & 0.03 \\
\hline RFC2 & -0.24 & 0.059 & 0.079 & -0.06 & 0.136 & $\begin{array}{l}-0.1 \\
\end{array}$ & 0.771 & 0.219 & 0.129 & -0.03 & $\begin{array}{l}-0.09 \\
\end{array}$ & -0.06 & 0.12 & 0.167 & -0.21 & -0.05 \\
\hline RFC3 & 0.12 & -0.03 & -0.05 & -0.01 & -0.1 & 0.071 & 0.891 & -0.06 & -0.04 & -0.04 & 0.055 & 0.016 & 0.032 & -0.07 & 0.152 & 0.011 \\
\hline PE1 & -0.09 & 0.028 & 0.06 & -0.15 & -0.07 & 0.075 & 0.07 & $\mathbf{0 . 8 3 5}$ & -0.02 & 0.396 & 0.02 & -0.08 & 0.048 & 0 & 0.075 & 0.117 \\
\hline PE2 & 0.038 & 0.077 & -0.12 & 0.096 & 0.021 & -0.02 & -0.02 & 0.93 & 0.005 & -0.14 & -0.01 & -0.05 & -0.01 & 0.05 & 0.006 & -0.12 \\
\hline PE3 & 0.047 & -0.11 & 0.065 & 0.042 & 0.046 & -0.05 & -0.05 & $\mathbf{0 . 8 8 5}$ & 0.017 & -0.23 & -0.01 & 0.123 & -0.04 & -0.05 & -0.08 & 0.019 \\
\hline FCP1 & 0.127 & -0.09 & -0.04 & 0.055 & -0.09 & -0.04 & 0.149 & -0.05 & $\mathbf{0 . 8 9 4}$ & 0.108 & 0.027 & -0.12 & 0.171 & -0.08 & 0.22 & -0.01 \\
\hline FCP2 & -0.06 & -0.12 & 0.078 & -0 & 0.081 & -0.04 & -0.11 & -0.01 & 0.889 & -0.05 & 0.049 & 0.039 & -0.03 & -0.03 & -0.11 & 0.058 \\
\hline FCP3 & -0.07 & 0.238 & -0.04 & -0.06 & 0.01 & 0.095 & -0.05 & 0.065 & 0.795 & -0.07 & -0.09 & 0.091 & -0.16 & 0.115 & -0.12 & -0.06 \\
\hline ITU1 & 0.025 & 0.041 & -0.03 & 0.003 & -0.02 & -0.02 & 0.04 & -0 & -0.03 & 0.965 & 0.045 & -0.05 & 0.051 & -0.02 & 0.052 & -0.01 \\
\hline ITU2 & -0.01 & -0.01 & 0.023 & 0.018 & 0.002 & 0.004 & 0 & -0.02 & 0.04 & 0.977 & -0.02 & -0.01 & -0.02 & 0.03 & -0.01 & -0.01 \\
\hline ITU3 & -0.02 & -0.03 & 0.006 & -0.02 & 0.014 & 0.011 & -0.04 & 0.026 & -0.01 & \begin{tabular}{|l|}
0.98 \\
\end{tabular} & -0.03 & 0.059 & -0.03 & -0.01 & -0.04 & 0.02 \\
\hline USE1 & 0.027 & 0.135 & -0.08 & 0.071 & -0 & 0.037 & 0.022 & -0.1 & 0.006 & 0.118 & 0.91 & -0.11 & 0.127 & -0.09 & 0.014 & 0.085 \\
\hline USE2 & 0.014 & 0.038 & -0.05 & -0.02 & -0.01 & 0.021 & 0.083 & 0.053 & -0.04 & 0.096 & 0.921 & 0.061 & 0.067 & 0.03 & -0.05 & -0.03 \\
\hline USE4 & -0.05 & -0.21 & 0.154 & -0.07 & 0.015 & -0.07 & -0.13 & 0.058 & 0.041 & -0.26 & $\mathbf{0 . 7 5 9}$ & 0.057 & -0.23 & 0.07 & 0.039 & $\begin{array}{c}-0.06 \\
\end{array}$ \\
\hline SI1 & 0.102 & -0.12 & -0.06 & -0.04 & 0.003 & 0.04 & 0.023 & -0.08 & -0.06 & 0.083 & 0.082 & 0.931 & 0.049 & -0.08 & 0.044 & 0.021 \\
\hline SI2 & -0.04 & 0.056 & -0 & 0.037 & -0.03 & -0.05 & 0.008 & -0.03 & 0.024 & 0.023 & 0.009 & $\begin{array}{c}0.938 \\
\end{array}$ & 0.128 & -0.07 & $\begin{array}{l}-0.13 \\
\end{array}$ & 0.113 \\
\hline SI3 & -0.06 & 0.065 & 0.06 & 0.003 & 0.029 & 0.006 & -0.03 & 0.104 & 0.033 & -0.11 & $\begin{array}{l}-0.09 \\
\end{array}$ & $\begin{array}{c}0.933 \\
\end{array}$ & -0.18 & 0.148 & 0.089 & -0.14 \\
\hline PI2 & -0.1 & 0.062 & -0.07 & -0.01 & 0.021 & -0.03 & -0.02 & 0.05 & -0.01 & -0.04 & 0.112 & -0.04 & $\mathbf{0 . 9 3 5}$ & -0.08 & -0.06 & 0.032 \\
\hline PI3 & 0.103 & -0.06 & 0.07 & 0.008 & -0.02 & 0.032 & 0.02 & -0.05 & 0.006 & 0.036 & -0.11 & 0.04 & $\mathbf{0 . 9 3 5}$ & 0.076 & 0.056 & -0.03 \\
\hline
\end{tabular}




\begin{tabular}{|c|c|c|c|c|c|c|c|c|c|c|c|c|c|c|c|c|}
\hline SUP1 & -0 & 0.028 & -0.03 & -0.03 & 0.092 & 0.095 & -0.12 & 0.056 & -0 & -0.06 & -0.14 & 0.087 & -0.09 & 0.91 & -0.02 & -0.04 \\
\hline$\overline{\text { SUP2 }}$ & 0.003 & $\begin{array}{l}-0.03 \\
\end{array}$ & 0.032 & 0.025 & $\begin{array}{l}-0.09 \\
\end{array}$ & -0.1 & 0.115 & -0.06 & 0.004 & 0.062 & 0.139 & $\begin{array}{l}-0.09 \\
\end{array}$ & 0.085 & 0.91 & 0.018 & 0.039 \\
\hline $\mathrm{FC} 1$ & -0.08 & 0.01 & -0.04 & -0.18 & 0.134 & 0.018 & -0.15 & 0.146 & -0.02 & -0.03 & -0.01 & -0.14 & 0.147 & -0.03 & 0.849 & 0.14 \\
\hline FC3 & 0.084 & -0.01 & 0.038 & 0.178 & -0.13 & -0.02 & 0.153 & -0.15 & 0.024 & 0.034 & 0.014 & 0.14 & -0.15 & 0.034 & 0.849 & -0.14 \\
\hline EE1 & 0.084 & -0.1 & 0.152 & -0.08 & 0.01 & 0.109 & -0.05 & 0.321 & 0.222 & $\begin{array}{l}-0.61 \\
\end{array}$ & 0.158 & 0.386 & 0.002 & -0.64 & 0.092 & 0.558 \\
\hline EE2 & -0.06 & 0.03 & -0.08 & -0.02 & -0.01 & -0.02 & -0.09 & -0.02 & -0.12 & 0.117 & -0.1 & -0.04 & $\begin{array}{l}-0.1 \\
\end{array}$ & 0.216 & 0.027 & 0.925 \\
\hline EE3 & 0.005 & 0.032 & -0.01 & 0.068 & 0.003 & -0.05 & 0.119 & -0.17 & -0.01 & 0.25 & 0.007 & -0.2 & 0.099 & 0.173 & -0.08 & 0.919 \\
\hline
\end{tabular}

Table 7 Factor loadings (bold) and cross loadings

We have now reviewed the initial information by doing a full collinearity check, predictive validity testing (Q-square), by looking for the presence of Simpson's paradox instances in the model and checking factor loadings and cross loadings. We conclude that the initial results indicate that the model findings are meaningful.

\section{Structural Model}

The structural model without interacting moderator variables is presented in Figure 2. All path coefficients are positive and statistically significant at $\mathrm{p}<0.05$, except for resource-facilitating conditions (RFC) to facilitating conditions (FC) with a coefficient of $-0,19$, technologyfacilitating conditions (TFC) to facilitating conditions (FC) with a coefficient of $-0,29$ and effort expectancy (EE) to intention to use (USE) with -0.05 as a coefficient. We follow the recommendation of Chin, Marcolin and Newsted (1996) in modeling the interaction effects by multiplying the corresponding indicators of the predictor and moderator constructs and implementing the hierarchical process to construct and compare research models with and without the respective interacting constructs. 


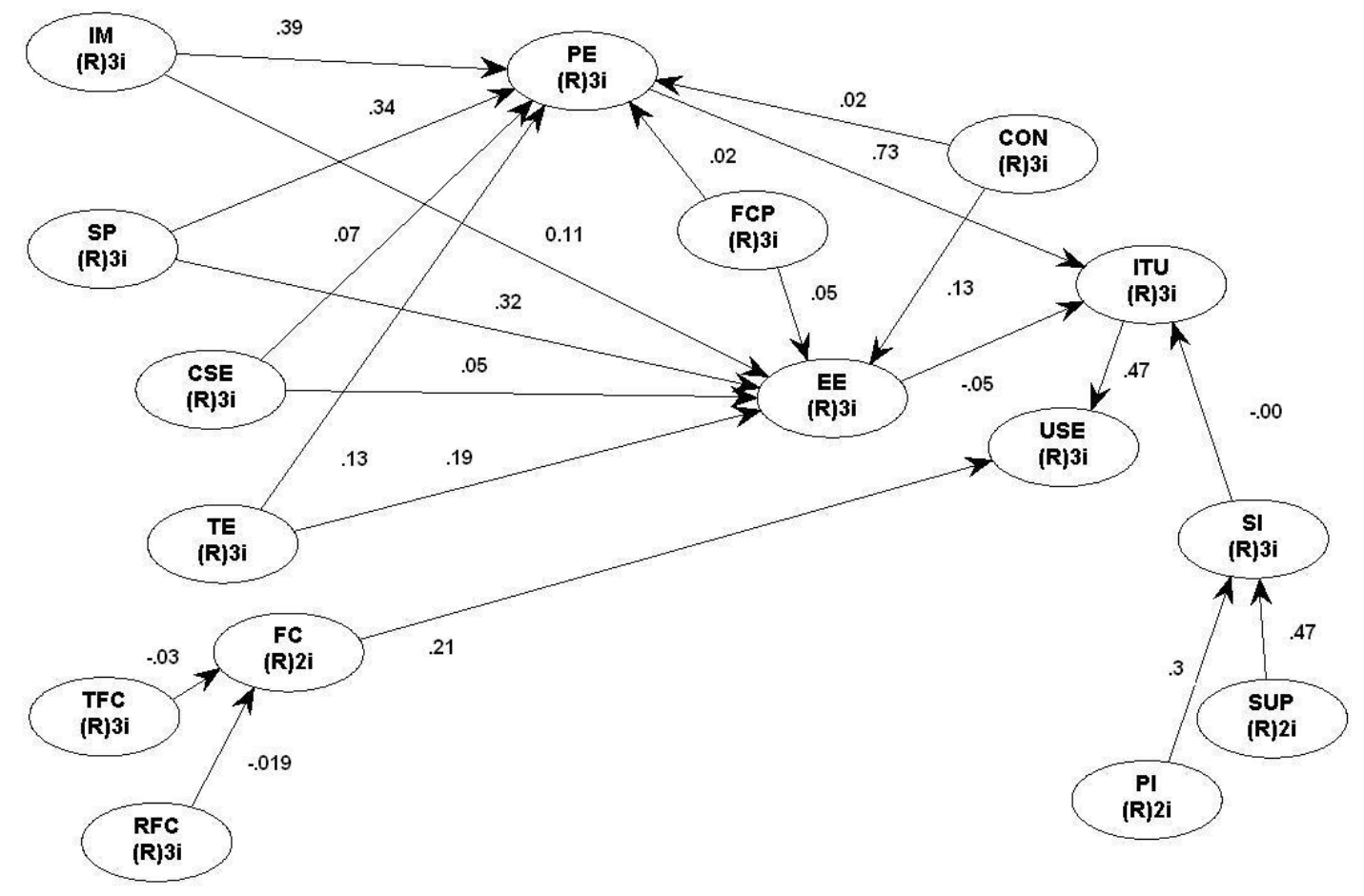

Figure 2 - Structural model results (without interacting variables - model 1)

Figure 3 shows the results of the structural model with interacting variables. It presents the results of the structural model with moderator variables. The beta values of all path coefficients are shown. Performance expectancy had a positive influence (beta $=0.73$ ) on intention to use. Effort expectancy had no influence (beta $=-0.05$ ) on intention to use. Facilitating conditions had a positive influence on use (beta $=0.21$ ). Behavioral intention had a positive influence (beta $=$ 0.47 ) on use. Social influence did not have any influence (beta $=0.00$ ) on intention to use. For the moderator variables (AGE, GEN and EXP), different interactive effects are observed: age had a positive effect on performance expectancy (beta=0.01) and negative effects on effort expectancy (beta=-0.18) and social influence (beta=-0.11). Gender had positive effects on performance expectancy (beta=0.04) and effort expectancy (beta=0.15) and a negative effect on social influence (beta=-0.00). Experience had negative effects on social influence (beta=-0.011) and facilitating conditions (beta $=-0.18$ ) and a positive effect on effort expectancy (beta=0.09). 


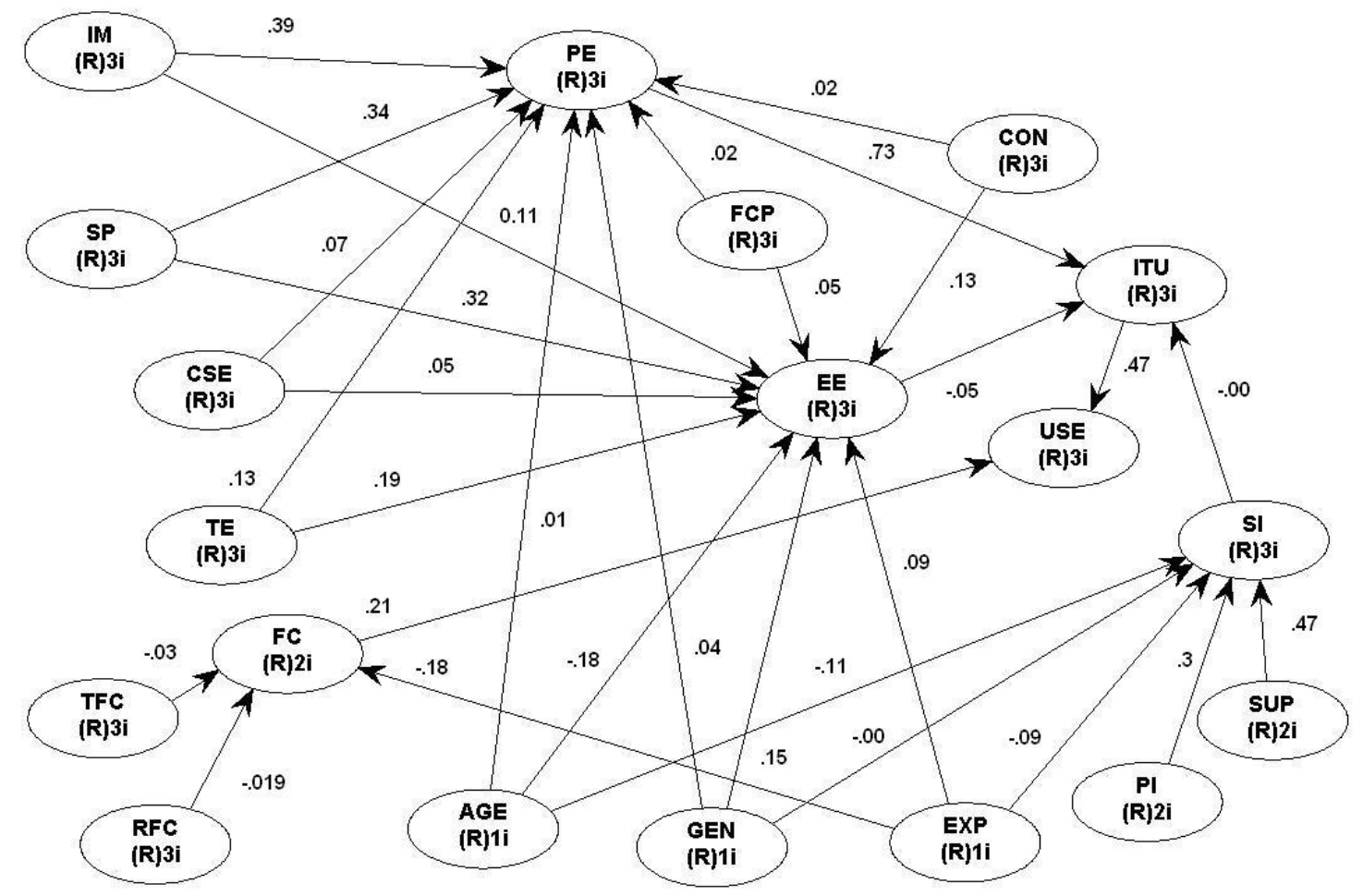

Figure 3 - Structural model results (with interacting variables - model 2)

The R2 value of 0.57 indicates that the theoretical model explained a substantial amount of variance in the use intention. In addition, 69 percent of the variance for attitude toward intention to use is accounted for by the model. Given the 10 percent minimum criterion which suggests that the R2 value of a dependent variable should be at least 10 percent in order to make any meaningful interpretation, the theoretical model demonstrated substantive explanatory power. In order to test the moderator variables in WarpPLS, we used multi-group analysis, using range restriction, and compared the results. The results of the hypotheses testing are shown in Table 8. 


\begin{tabular}{|c|c|c|}
\hline Hypotheses & $\begin{array}{l}\text { Parameter } \\
\text { estimates }\end{array}$ & Result \\
\hline $\begin{array}{l}\text { Hypothesis 1a: The effect of performance expectancy on intention to use of UC\&C technology will } \\
\text { be moderated by gender and age such that it is strongest for younger men. }\end{array}$ & 0.87 & Supported \\
\hline $\begin{array}{l}\text { Hypothesis } 1 \mathrm{~b} \text { : The effect of facilitating conditions on use of UC\&C technology use will be } \\
\text { moderated by age and experience, such that the effect is stronger for older users, particularly those } \\
\text { with little experience. }\end{array}$ & 0.16 & Supported \\
\hline Hypothesis 2a: Social presence will positively influence performance expectancy & 0.34 & Supported \\
\hline Hypothesis 2b: Social presence will positively influence effort expectancy & 0.32 & Supported \\
\hline Hypothesis 2c: Immediacy of communication will positively influence performance expectancy. & 0.38 & Supported \\
\hline Hypothesis 2d: Immediacy of communication will positively influence effort expectancy. & 0.07 & Not supported \\
\hline Hypothesis 2e: Concurrency will positively influence performance expectancy. & 0.01 & Not supported \\
\hline Hypothesis 2f: Concurrency will positively influence effort expectancy. & 0.09 & Not supported \\
\hline Hypothesis 3a: UC\&C technology experience will positively influence performance expectancy. & 0.13 & Not supported \\
\hline Hypothesis 3b: UC\&C technology experience will positively influence effort expectancy. & 0.22 & Not supported \\
\hline Hypothesis 3c: Computer self-efficacy will positively influence performance expectancy. & 0.07 & Not supported \\
\hline Hypothesis 3d: Computer self-efficacy will positively influence effort expectancy. & 0.03 & Not supported \\
\hline $\begin{array}{l}\text { Hypothesis 3e: Familiarity with communication partners will positively influence performance } \\
\text { expectancy. }\end{array}$ & 0.02 & Not supported \\
\hline Hypothesis 3f: Familiarity with communication partners will positively influence effort expectancy. & 0.04 & Not supported \\
\hline Hypothesis 4a: The influence of peers will positively influence the perception of social influence. & 0.36 & Supported \\
\hline $\begin{array}{l}\text { Hypothesis } 4 \mathrm{~b} \text { : The influence of superiors will positively influence the perception of social } \\
\text { influence. }\end{array}$ & 0.44 & Supported \\
\hline $\begin{array}{l}\text { Hypothesis } 4 \mathrm{c} \text { : Resource-facilitating conditions will positively influence the perception of } \\
\text { facilitating conditions. }\end{array}$ & -0.22 & Not supported \\
\hline $\begin{array}{l}\text { Hypothesis } 4 \mathrm{~d} \text { : Technology-facilitating conditions will positively influence the perception of } \\
\text { facilitating conditions. }\end{array}$ & -0.09 & Not supported \\
\hline Hypothesis 5: Behavioral intention will positively influence use. & 0.47 & Supported \\
\hline
\end{tabular}

Table 8 Hypotheses results

\section{DISCUSSION}

Table 7 presents the hypotheses and the results. Eight out of nineteen hypotheses proved to be statistically significant by a significance level of 5 percent. The result column indicates whether the hypothesis was supported or not supported.

To better understand the effect of adding the three new variables (gender, age and experience) to Model 1, we compared Model 1 to Model 2. The addition of the three variables did not have any influence on the path coefficients of the four main constructs: PE, EE, SI and FC.

Performance expectancy (PE) is the most important construct in user acceptance and use, as successful introduction of UC\&C technology in organizations requires the greatest attention to performance expectancy. If an employee of an organization believes that using UC\&C technology will increase his productivity, it will lead to increased technology use. Effort expectancy (EE) did not have any impact on the introduction of the new technology. This can be interpreted as the effect of having productivity effects prioritized over the ease of use and the fact 
that employees do not mind a decrease in ease of use, being more willing to go for the perceived benefits.

Social influence (SI) had a significant influence on the UC\&C introduction and this is consistent with the original UTAUT study.

Facilitating conditions (FC) were consistent in both models and remained unchanged. This also explains the fact that when an organizational and technical infrastructure is present it facilitates the use of the UC\&C technology inside the organization.

A full understanding of the impact of the above dimensions will impact on the adoption of the UC\&C technology and drive employee productivity and the use of the technology.

\section{Limitations and Future Research}

There are several limitations to our research. First, the study addressed employees in 34 different countries but only one or two respondents were identified from 15 of those countries. Future studies should involve more participants in order to increase the generalizability of the findings. Secondly, the study was not longitudinal in design, which should be addressed by future studies to include a multi-cultural aspect with longitudinal design. Thirdly, previous studies confirmed that age influences the use where age was proved to be linked with gender, especially for women. In our study, the ages of respondents did not vary very much. Future research should address better age and gender interactions.

Future research should incorporate multi-cultural and organizational culture dimensions using Hofstede's cultural dimensions (Hofstede, Neuijen \& Ohayv, 1990) or an individual measure of the organizational culture.

\section{Implications for Practice}

Our study focused on Microsoft Lync Unified Communications \& Collaboration technology that was implemented in a Fortune 500 company. Regardless of the UC\&C technology that organizations implement, our research findings can be implemented in a very practical way. In this section, we show an example of how to achieve a successful project implementation when introducing UC\&C technology. We will analyze and explain the different factors which drive the successful implementation of new technology and, most importantly, increase organizational productivity and employees' performance.

When introducing $\mathrm{UC} \& \mathrm{C}$ technology, an important aspect to consider is training. When employees or end-users receive very advanced training on the various possibilities that UC\&C technology can offer, such as simplifying their daily activities or enabling them to communicate faster with their peers, it will prove to be very valuable as employees will get a fuller understanding of the technological benefits to their own performance. Thus, we suggest that organizations perform advanced training sessions for employees to introduce them to all of the technological benefits that will impact and increase their job performance. Also, we recommend to organizations to strongly focus their efforts on older employees who do not accept new technology easily. Indeed, they tend not to use it and usually reject the introduction of technology. 
As it becomes more important for organizations to have a strong social presence, it is recommended that they place a focus on those social presence aspects which allow employees, through concrete examples, to see some best practices of how social presence strategies can efficiently be used. Moreover, when organizations are coping with multi-cultural aspects, it is very important to understand diversity and to demonstrate good practice to employees. This can include sharing good practice when it comes to the language used in communication or emoticons that are appropriate for communication with peers from different cultural backgrounds.

Another very important aspect which the organization should evaluate with a high priority relates to technological characteristics. As employees are very sensitive about how technology answers their needs and problems, technological characteristics should be carefully evaluated; we suggest doing pilot tests with selected employees to understand whether or not the technological characteristics meet the employees' needs. Technological characteristics have an important impact on employees' job performance and directly impact the outcomes of immediacy and concurrency. Employees want fast communication, fast video and messaging features and all combined with the fact that most of them also want to use these features while doing other tasks. One of the pitfalls of some UC\&C technologies is that they do not meet these end user expectations and thus, fail in their implementation.

Once organizations have evaluated the technological characteristics and have successfully conducted pilot tests with selected employees, the next step is to ensure that employees are using the technology; as not matter how successful and smooth the implementation is, without the employees really using the technology, the result will probably be a failure. In this context, the influence of peers and superiors is the key driver for technology usage, as there is no better way to promote the technology internally than by using internal networks created between different departments, cross-functional organizations, and so on.

Overall, from a practical standpoint there are several steps that can be of the highest importance in driving technology adoption within organizations. These steps can be summarized in the following way:

1) Choice of different UC\&C platforms

2) Technological characteristics presentation

3) Pilot tests with selected employees

4) Training on the selected UC\&C platform

5) Social presence tips \& tricks

6) Internal peers' influence

By following these six practical steps, we believe organizations will be able to adopt UC\&C technology faster, cheaper and more successfully. The employees' performance will benefit from all aspects related to the technology implementation. Moreover, the multi-cultural context, which represents an important aspect of the technology introduction, will be considered in an appropriate way, enabling international organizations to implement the technology across different countries. 
Finally, we believe that taking these small but important steps will help organizations to make important cost savings, as it is not only important to implement the technology but also to teach employees and end-users how to utilize it.

\section{CONCLUSION}

This research used the UTAUT model combined with collaboration theory to understand employee adoption of UC\&C technology in cross-cultural organizations. Following the suggestion of Venkatesh (2000), we found that behavioral intention had a positive effect on the intention to use UC\&C technology. The effects of performance expectancy and facilitating conditions were both moderated by gender-age and age-experience respectively. Contrary to Brown et al. (2010)'s findings, we found that social presence did not positively influence effort expectancy, but had a positive effect on performance expectancy.

Thus, our findings are mainly consistent with previous studies but we also found some surprising results in which concurrency, technology experience, computer self-efficacy and familiarity with communication partners did not have any impact on either the performance expectancy or the effort expectancy.

Our study will be useful for organizations introducing UC\&C technology or for trying to understand eventual failures in the adoption of UC\&C technology. As expected, organizations are mostly concerned about the final results where productivity is the key driver and should be sold as the main benefit to employees. The study also shows that focus should be given to female employees related to performance expectancy. Moreover, the influence of peers and superiors appears to be of high importance and, together with the productivity driver, represents the best argument for organizations to boost adoption.

Overall, this research has provided some useful insights into how to effectively adopt UC\&C technology in organizations within a cross-cultural context, and explains the main factors influencing employee acceptance of the UC\&C technology in the organization.

\section{References}

Al-Gahtani, S. S., Hubona, G. S., \& Wang, J. (2007). Information technology (IT) in Saudi Arabia: Culture and the acceptance and use of IT. Information \& Management, 44(8), 681-691. doi: http://dx.doi.org/10.1016/j.im.2007.09.002

Anderson, J. E., Schwager, P. H., \& Kerns, R. L. (2006). The Drivers for Acceptance of Tablet PCs by Faculty in a College of Business. Journal of Information Systems Education, 17(4), 429440.

Bajwa, D. S., Lewis, L. F., Pervan, G., \& Lai, V. S. (2005). The adoption and use of collaboration information technologies: international comparisons. Journal of Information Technology (Palgrave Macmillan), 20(2), 130-140. doi: 10.1057/palgrave.jit.2000037

Bajwa, D. S., Lewis, L. F., Pervan, G., Lai, V. S., Munkvold, B. E., \& Schwabe, G. (2008). Factors in the Global Assimilation of Collaborative Information Technologies: An Exploratory Investigation in Five Regions. Journal of Management Information Systems, 25(1), 131-165. 
Baškarada, S., \& Koronios, A. (2012). Exploring the Effects of Enterprise Instant Messaging Presence Information on Employee Attendance in a Distributed Workforce: An Ethnographic Study of a Large Professional Services Organization. International Journal of e-Collaboration (IJeC), 8(3), 1-18. doi:10.4018/jec.2012070101

Brown, S. A., Dennis, A. R., \& Venkatesh, V. (2010). Predicting Collaboration Technology Use: Integrating Technology Adoption and Collaboration Research. Journal of Management Information Systems, 27(2), 9-53. doi: 10.2753/MIS0742-1222270201

Cabrera, N., Cabrera, E. F., Sebasti, \#225, \& Barajas, N. (2001). The key role of organizational culture in a multi-system view of technology-driven change. Int. J. Inf. Manag., 21(3), 245-261. doi: 10.1016/s0268-4012(01)00013-5

Camarinha-Matos, L. M., Afsarmanesh, H., Galeano, N., \& Molina, A. (2009). Collaborative networked organizations - Concepts and practice in manufacturing enterprises. Computers \& Industrial Engineering, 57(1), 46-60. doi: http://dx.doi.org/10.1016/j.cie.2008.11.024

Chin, W. W., Marcolin, B. L., \& Newsted, P. R. (2003). A Partial Least Squares Latent Variable Modeling Approach for Measuring Interaction Effects: Results from a Monte Carlo Simulation Study and an Electronic-Mail Emotion/Adoption Study. Information Systems Research, 14(2), 189-217.

Chin, W. W., Marcolin, B. L., \& Newsted, P. R. (2003). A Partial Least Squares Latent Variable Modeling Approach for Measuring Interaction Effects: Results from a Monte Carlo Simulation Study and an Electronic-Mail Emotion/Adoption Study. Information Systems Research, 14(2), 189-217.

Chow, C. W., Deng, F. J., \& Ho, J. L. (2000). The Openness of Knowledge Sharing within Organizations: A Comparative Study of the United States and the People's Republic of China. Journal of Management Accounting Research, 12, 65-95.

Dasgupta, S., Agarwal, D., Ioannidis, A., \& Gopalakrishnan, S. (1999). Determinants of information technology adoption: an extension of existing models to firms in a developing country. J. Glob. Inf. Manage., 7(3), 30-40.

Dennis, A.R., \& Gallupe, R.B. (1993). A history of GSS empirical research: Lessons learned and future directions. In L.M. Jessup and J.S. Valacich (eds.), Group Support Systems: New Perspectives pp. 59-77. New York: Macmillan.

Dennis, A. R., \& Garfield, M. J. (2003). The Adioption and use of GSS in project teams: Toward more participative processes and outcomes. Mis Quarterly, 27(2), 289-323.

Dennis, A. R., George, J. F., Jessup, L. M., Nunamaker Jr, J. F., \& Vogel, D. R. (1988). Information Technology to Support Electronic Meetings. Mis Quarterly, 12(4), 591-624. 
Dent, J., \& Green, S. (1985). "Notes towards a Framework for the Cross-Cultural Analysis of Accounting Practice". European Institute for Advanced Studies in Management Conference on Accounting and Culture, Amsterdam, Netherlands.

DeSanctis, G., \& Poole, M. S. (1994). Capturing the Complexity in Advanced Technology Use: Adaptive Structuration Theory. Organization Science, 5(2), 121-147.

Drakos, N. (2009) - Key Issues for Social Software and Collaboration Initiatives, 2009. Gartner Research, ID No. G00164866, Retrieved Jan. 30.

Fedrick, M. A. C. (2001). The Relationship Between Organizational Culture and the Processes for Implementing Technology at Selected Private Liberal Arts Colleges. The Pennsylvania State University.

Fjermestad, J., \& Hiltz, S. R. (2000). Group Support Systems: A Descriptive Evaluations of Case and Field Studies. Journal of Management Information Systems, 17(3), 115-159.

Fjermestdad, J., \& Hiltz, S. R. (1998). An Assessment of Group Support Systems Experimental Research: Methodology and Results. Journal of Management Information Systems, 15(3), 7-149.

Fornell, C., \& Larcker, D. F. (1981). Evaluating Structural Equation Models with Unobservable Variables and Measurement Error. Journal of Marketing Research (JMR), 18(1), 39-50.

Frost, S. (2007). Meetings around the world: The impact of collaboration on business performance. Frost \& Sullivan White Paper, Palo Alto, CA.

Geisser, S. (1974). A predictive approach to the random effects model. Biometrika, 61(1), 101107.

Harper, G. R., \& Utley, D. R. (2001). Organizational Culture and Successful Information Technology. Implementation. Engineering Management Journal.

Hofstede, G., Neuijen, B., Ohayv, D. D., \& Sanders, G. (1990). Measuring Organizational Cultures: A Qualitative and Quantitative Study across Twenty Cases. Administrative Science Quarterly, 35(2), 286-316.

Hulland, J.U se of partial least squares (PIS) in strategic management research: A review of four recent studies. Strategic Management Journal,20,2 (1999), 195-204.

Karahanna, E., \& Straub, D. W. (1999). The psychological origins of perceived usefulness and ease-of-use. Information \& Management, 35(4), 237-250. doi: http://dx.doi.org/10.1016/S03787206(98)00096-2

Kitchell, S. (1995). Corporate culture, environmental adaptation, and innovation adoption: A qualitative/quantitative approach. Journal of the Academy of Marketing Science, 23(3), 195-205 LA - English. doi: 10.1177/0092070395233004 
Kock, N. (2003). Action research: Lessons learned from a multi-iteration study of computermediated communication in groups. IEEE Transactions on Professional Communication, 46(2), 105-128.

Kock, N. (2005). What is E-Collaboration? International Journal of e-Collaboration, 1(1), i-vii.

Kock, N., \& Nosek, J. (2005). Expanding the Boundaries of E-Collaboration. IEEE Transactions on Professional Communication, 48(1), 1-9.

Kraut, R. E., Rice, R. E., Cool, C., \& Fish, R. S. (1998). Varieties of Social Influence: The Role of Utility and Norms in the Success of a New Communication Medium. Organization Science, $9(4), 437-453$.

Laso-Ballesteros, I., \& Salmelin, B. (2005). AMI-endowed collaboration@work. In G. Riva, F. Vatalaro, F. Davide, \& M. Alcaniz (Eds.), Ambient Intelligence: The evolution of technology, communication and cognition towards the future of human-computer interaction (pp. 237-265). Amsterdam, The Netherlands: IOS Press.

Li, D., Chua, P. Y. K., \& Lu, H. (2005). Understanding Individual Adoption of Instant Messaging: An Empirical Investigation. Journal of the Association for Information Systems, 6(4), 102-129.

MacCormack, A., \& Forbath, T. (2008). Learning the Fine Art of Global Collaboration. Harvard Business Review, 86(1), 24-26.

Pervan, G., Bajwa, D. \& Lewis, L.F.(2005). A study of the adoption and utilization of seven collaboration technologies in large organizations in Australia and New Zealand. Journal of Global Information Technology Management.

Pettigrew, A. M. (1990). Organizational Climate and Culture: Two Constructs in Search of a Role. Organizational Climate and Culture, B. Schneider (ed.) pp. 413-433., Jossey-Bass, San Francisco.

Rosenthal, R., \& Rosnow, R.L. (1991). Essentials of Behavioral Research: Methods and Data Analysis. Boston, MA: McGraw Hill.

Smircich, L. (1983). Concepts of Culture and Organizational Analysis. Administrative Science Quarterly, 28(3), 339-358.

Smith, H. A., \& McKeen, J. D. (2011). Enabling Collaboration with IT. Communications of AIS, 28, 243-254.

Straub, D.W.; Boudreau, M.; \& Gefen, D. Validation guidelines for IS positivist research. Communications of the Association for Information Systems, 13, 1 (2004), 380-427 
Straub, D., \& Karahanna, E. (1998). Knowledge Worker Communications and Recipient Availability: Toward a Task Closure Explanation of Media Choice. Organization Science, 9(2), 160-175.

Straub, D., Loch, K., Evaristo, R., Karahanna, E., \& Srite, M. (2002). Toward a Theory-Based Measurement of Culture. Journal of Global Information Management (JGIM), 10(1), 13-23. doi:10.4018/jgim.2002010102

Stone, M. (1974). Cross-validatory choice and assessment of statistical predictions. Journal of the Royal Statistical Society, Series B, 36(1), 111-147.

Syler, R. A. (2003). Exploring the Fit of Organizational Culture Traits and Information Technology Infrastructure Flexibility: A Partial Least Squares Latent Variable Modeling Approach: Auburn University.

Taylor, S., \& Todd, P. A. (1995). Understanding Information Technology Usage: A Test of Competing Models. Information Systems Research, 6(2), 144-176.

Venkatesh, V. (2000). Determinants of Perceived Ease of Use: Integrating Control, Intrinsic Motivation, and Emotion into the Technology Acceptance Model. Information Systems Research, 11(4), 342-342.

Venkatesh, V., \& Davis, F. D. (1996). A Model of the Antecedents of Perceived Ease of Use: Development and Test. Decision Sciences, 27(3), 451-481.

Venkatesh, V., Morris, M. G., Davis, G. B., \& Davis, F. D. (2003). User acceptance of information technology: Toward a unified view. Mis Quarterly, 27(3), 425-478.

Whinston, A. B. (1993). Introduction to the Special Issue: Organizational Computing Coordination and Collaboration. Journal of Organizational Computing \& Electronic Commerce, 3(1), iii-iii. 